\title{
入藏旅游流网络结构特征与组织模式 基于团队游和自助游视角的比较分析
}

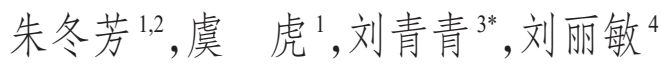 \\ (1. 中国科学院地理科学与资源研究所, 中国科学院区域可持续发展分析与模拟重点实验室, 北京 100101 ; \\ 2. 中国科学院大学资源与环境学院, 北京 $100049 ; 3$. 河南财经政法大学旅游与会展学院,郑州 450000 ; \\ 4. 中华女子学院管理学院, 北京 100101)
}

\begin{abstract}
摘 要:西藏作为大尺度景观区域,旅游资源分布、景观格局、交通线路等具有遍在性和分散化特征,加之地形、海 拔、气候等自然条件差异性和多变性,使人藏旅游流特征与其他类型地区截然不同,团队游、自助游的细分差异尤 为显著。论文采集热门旅游网站人藏团队游和自助游线路数据, 结合社会网络分析探讨人藏旅游流的网络结构特 征与组织模式, 为西藏区域旅游优化组织提供理论借鉴。研究发现: 人藏旅游流总体集聚、层级分化, 节点联系总 体不紧密, 核心一边缘结构明显, 其中团队游对枢纽节点和交通的依赖性较强, 自助游覆盖地域较大、分布相对均 衡; 团队游和自助游旅行模式分别呈现为“环游式”和“周游式”, 网络紧凑板块的“跨行政区”现象突出, 受控于交通 干线的程度较深; 人藏团队游和自助游旅游流之间的差异反映了地形、海拔、交通、旅游资源分布以及消费能力等 多方面的交叉影响, 是不同旅游动机下个体和群体面向多因素综合作用的空间决策结果, 进而影响西藏旅游交通 布局、旅游产品组合、区域旅游协作等。研究结果对于认知人藏团队游和自助游游客的流动模式和移动规律具有 参考意义, 可以为西藏旅游线路优化设计、旅游地协同规划提供指引。
\end{abstract}

关 键 词: 人藏旅游流网络; 组织模式; 大尺度景观区域; 西藏

不同空间位置主体之间的地理流动塑造了地 理空间格局,并成为推动地域系统演化的关键动力 因素 ${ }^{[1]}$ 。旅游流的地理空间流动反映了旅游者在客 源地与目的地之间流动的数量和模式 ${ }^{[2]}$ 。旅游线 路、旅游流和旅游地空间结构环环相扣, 旅游流结 构模式演化较大地影响着沿线旅游产品建设、旅游 设施配套、目的地营销与管理方式 ${ }^{[3]}$, 三者之间的 作用推动着区域旅游目的地系统的形成与持续演 化 ${ }^{[4-5]}$ 。随着信息化手段的不断丰富, 传统团队游正 在向个人化、定制化方式转变, 由此引发的旅游流 组织模式、动力机制的改变, 正在重塑新的旅游地 域格局。团队游和自助游分别代表了传统和现代
旅游选择行为模式, 开展对比分析有利于认识旅游 流的类型分异规律和指导实践应用。

目前旅游流研究主要关注其概念内涵和理论 框架 ${ }^{[6-7]} 、$ 旅游流时空结构特征 ${ }^{[8-10]}$ 、旅游流动力机制 和影响因素 ${ }^{[1-12]}$ 以及旅游流的流动效应 ${ }^{[13-14]}$ 等; 在研 究方法上, 社会网络分析 ${ }^{[15]}$ GIS 空间分析 ${ }^{[16]}$ 、旅游流 集聚与扩散指数 ${ }^{[17]} 、$ 旅游数字足迹 ${ }^{[18]} 、$ 重心模型 ${ }^{[4]} 、$ 耦 合度模型 ${ }^{[19]}$ 、灰色关联分析 ${ }^{[20]}$ 等方法得到广泛应用。 在研究案例上, 主要集中于全国旅游流研究 ${ }^{[21-23]}$ 、省 区旅游流研究 ${ }^{[4,24-26]}$ 、城市间旅游流研究 ${ }^{[27-28]}$ 、城市内 部旅游流研究 ${ }^{[29]}$ 以及景区内部旅游流研究 ${ }^{[30]}$ 。省域 层面的旅游流研究内容聚焦于旅游流时空特征、集

收稿日期: 2020-07-27; 修订日期: 2020-10-29。

基金项目:第二次青藏高原综合科学考察研究项目(2019QZKK0401); 中国科学院 A类战略性先导科技专项(XDA20020302)。

[Foundation: The Second Comprehensive Scientific Investigation and Study on the Qinghai-Tibet Plateau, No. 2019QZ-

KK0401; The Strategic Priority Research Program of the Chinese Academy of Sciences, No. XDA20020302. ]

第一作者简介: 朱冬芳(1987-), 女, 安徽庐江人, 博士生, 研究方向为旅游地理与生态旅游。E-mail: zdfashd@163.com

*通信作者简介: 刘青青(1987-), 女, 河南郑州人, 博士, 讲师, 从事城市旅游和旅游管理研究。E-mail: qingqinghuel@sina.com

引用格式: 朱冬芳, 虞虎, 刘青青, 等. 入藏旅游流网络结构特征与组织模式: 基于团队游和自助游视角的比较分析 [J]. 地理科学进展, 2021, 40(5): 812-824. [Zhu Dongfang, Yu Hu, Liu Qingqing, et al. Network structure characteristics and organizational models of tourist flow to Tibet: Comparative analysis based on group and self-guided tours. Progress in Geography, 2021, 40(5): 812-824. ] DOI: $10.18306 /$ dlkxjz.2021.05.008 
聚与扩散规律、演变特征及其影响因素 ${ }^{[31-32]}$ 等维度, 且主要在大都市、城市群地区开展, 针对大尺度景 观区域的旅游流研究较少, 因为景观相对均质与线 路单一化地区, 旅游线路组织和流动方式与城市地 区存在较大不同, 产生了特定的组织模式。西藏地 处青藏高原腹地, 是中国重要的边疆民族地区。习 近平总书记在 2019 年 6 月致“2019・中国西藏发展 论坛”的贺信中指出, 西藏是“重要的中华民族特色 文化保护地和重要的世界旅游目的地”。自 20 世纪 80 年代西藏对旅游者开放以来, 西藏旅游人数规模 呈指数式增长, 逐渐成为西藏经济社会发展的变革 性力量, 但是对西藏旅游发展的研究严重滞后于社 会发展的需求。目前关于西藏旅游的研究主要集 中在旅游感知与体验 ${ }^{[33-34]}$ 、旅游产品开发设计 ${ }^{[3-36]}$ 、 旅游发展策略 ${ }^{[37}$ 等内容, 关于西藏旅游流的研究成 果极少, 在区域旅游规划、旅游产业布局、设施配套 等方面也缺乏相应的学术成果借鉴。相比于当前 旅游流关注的城市化地区, 西藏旅游表现为景观的 全域化、物质和非物质文化旅游景点的多样化、交 通体系发育的单一化、高海拔环境的限制性等, 使 西藏旅游流表现出与以往研究案例地完全不同的 发展特点, 该区的研究将有助于发展不同类型地域 旅游流模式与空间组织理论, 指导西藏旅游地可持 续发展。

鉴于此, 本文采用网络挖掘方法建构人藏旅游 流数据库, 结合社会网络分析方法对比研究人藏旅 游流结构特征, 以期为丰富旅游流空间模式和西藏 旅游发展提供理论参考。

\section{1 案例地、数据与方法}

\section{1 案例地概况}

西藏自治区位于青藏高原西部, 享有“世界屋 脊” “地球第三极”之称, 国土总面积 120.22 万 $\mathrm{km}^{2}$, 约占全国国土总面积的 1/8(图 1)。下辖拉萨市、日 喀则市、昌都市、林芝市、山南市、那曲市、阿里地区 7 个地级市、 74 个县(区), 为中国 5 个少数民族自治 区之一。境内拥有珠穆朗玛峰、冈仁波齐、雅鲁藏 布江大峡谷、南伽巴瓦峰、布达拉宫等世界级旅游 资源。2018 年, 共有各类风景资源点 1400 多处, A 级景区 117 处,其中国家 5A 级旅游景区 4 处、4A 级 景区 12 处; 接待国内外旅游者 3368.73 万人次, 旅游 总收人 490.14 亿元(约占全区国内生产总值的 $33.17 \%$ ), 自驾游快速增长。

西藏高寒高原环境独特性使旅游流发展与其 他地区表现为截然不同的特点, 主要表现在: (1) 自 然和人文旅游资源异质性强、复合性高。从珠穆朗 玛峰到墨脱热带雨林, 拥有冰川荒漠、高山草甸、河 湖湿地、高山森林等多类型、大尺度景观,集中了全 系列旅游景观图谱, 点缀着以藏族为代表的复合性 民族文化资源, 表现出全区域、全谱系、全景观的综 合体系, 决定了旅游流动分散式的复合特点。(2)高 原自然环境条件的限制性。西藏平均海拔 $4000 \mathrm{~m}$ 以上地区占 $85.1 \%$, 那曲、阿里部分城镇所在地海拔 $4500 \mathrm{~m}$ 以上,高原缺氧现象明显,体感环境多变,对 旅游线路选择的限制性较强,进而使不同游客群体 形成差异化的组织方式。(3) 交通体系与城镇组合

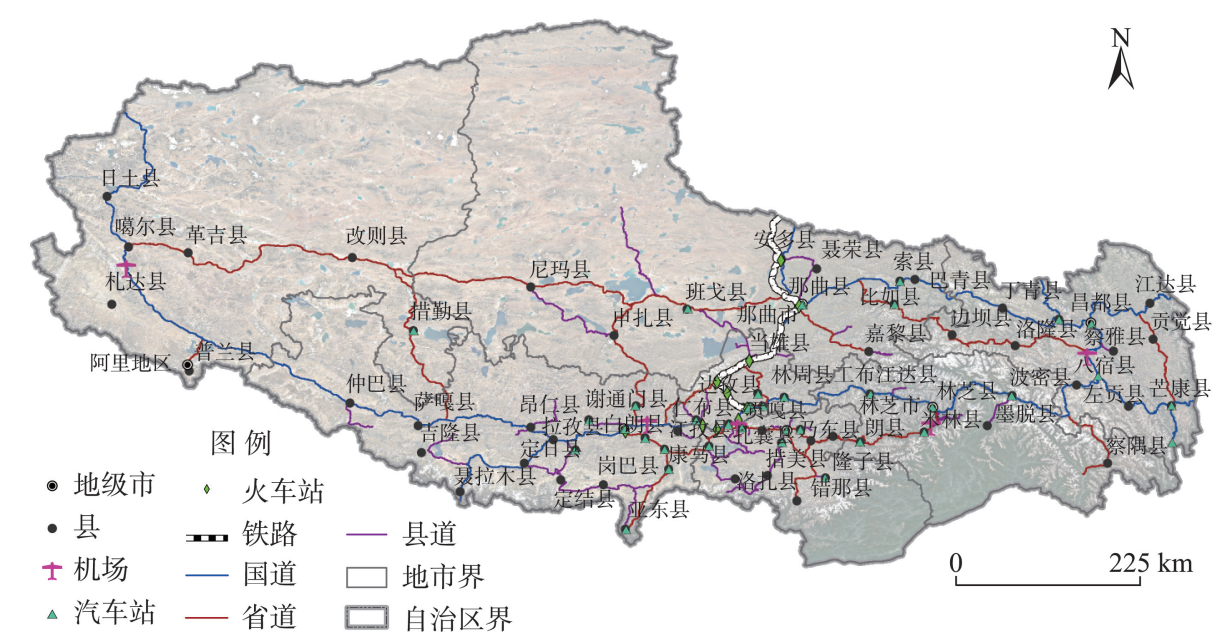

注: 本图基于自然资源部标准地图服务网站下载的审图号为 GS(2019)3333 号的标准地图制作,底图无修改。

图 1 西藏自治区城镇体系与交通路网基本情况

Fig.1 Urban system and traffic network in Tibet Autonomous Region 
的单一性。西藏城镇发展主要沿“一江两河”分布, 沿主干道串珠状分布特点明显, 城镇、乡镇之间的 距离长达几十公里甚至上百公里, 交通线路单一, 依托城镇规模小、人口少, 旅游服务配套短板较大, 进一步影响了旅游流的空间流动格局。西藏旅游 流发展特征与模式的研究, 有助于探索这一类特殊 地区的旅游流发展特征, 增进旅游流研究领域的新 类型发现与探索。

\section{2 数据来源}

旅游线路是研究旅游流空间流动模式和规律 的重要依据。本文的数据来源主要来自于主流旅 游网站公开的旅游线路数据, 进行批量下载、数据 建库和信息挖掘。本文从旅行社官方网站和网络 游记分别获取团队游和自助游的线路数据, 时间段 为 2019 年 $1-12$ 月。其中, 自助游的线路数据主要 来源于途牛网、驴妈妈网、蚂蜂窝网、携程网等网站 发布的旅游者游记; 团队游线路数据来源于同时段 全国百强旅游社发布的西藏旅游线路报价单, 处理 时剔除同一账号的重复线路。团队游和自助游线 路分别获取 501 、585 条。

将西藏各区县级城镇作为旅游节点, 通过旅游 线路联系构建目的地网络联系, 形成有向旅游流网 络矩阵。将所有线路数据录人 Excel 中, 构建西藏 县级行政单元的旅游节点非对称赋值矩阵; 然后将 其加载到 Ucinet 软件中, 经过反复试验, 为获得较 好的网络解释, 最终将切分值选择为 1 : 当城镇之间 线路连接数量大于或等于 1 时, 数值转化为 1 ; 反之 记为 0 , 获得二分矩阵, 并在此基础上运用Ucinet 软 件分析人藏旅游流网络特征。

\section{3 研究方法}

Ucinet社会网络分析是旅游流研究的主要方 法之一, 它通过一系列网络测算指标来解释旅游 流网络的结构特征, 揭示网络节点的等级性和层 次性 ${ }^{[38]}$ 。本文采用整体网络结构指标和单个节点 结构指标评价人藏旅游者的团队游和自驾游的网 络结构特征并进行对比分析。

(1) 网络规模。表示旅游流网络中的所有节点 数量, 用于测度旅游者到访的旅游目的地数量。网 络规模的大小与旅游者到访的旅游目的地数量呈 正相关关系。如果旅游流网络中有 $n$ 个节点, 有向 网络中的网络规模为 $n(n-1)$ 。

(2) 网络密度。指旅游流网络中实际存在的关 系数量与所有理论上可能存在的关系数量之比, 用
来衡量人藏旅游流网络中各旅游节点间联系的紧 密程度。网络密度越大, 表明旅游流网络中旅游节 点之间的连接线路越多, 节点联系越紧密。若旅游 流有向关系网络中有 $n$ 个旅游节点, 网络的实际关 系为 $L$, 理论上最大的关系值是 $n(n-1)$, 则网络密度 为 $L /[n(n-1)]$ 。使用 Ucinet 中的 Network/cohesion/ density 模块计算。

(3) 节点中心性。反映旅游节点在人藏旅游流 网络中的中心地位和重要程度, 包括程度中心性、 中介中心性和接近中心性 3 个指标。程度中心性可 衡量人藏旅游流网络中旅游节点的集聚与辐射能 力; 中介中心性刻画的是某些旅游节点对其他旅游 节点的控制和依赖程度; 接近中心性测度的是某些 旅游节点与其他节点联系的紧密程度。通过Ucinet 软件的 Network/Centrality模块计算。

$$
\begin{gathered}
C_{\mathrm{AD}, \text { in }}\left(n_{i}\right)=\sum_{j=1}^{g} r_{i j, \text { in }} \\
C_{\mathrm{AD}, \text { out }}\left(n_{i}\right)=\sum_{j=1}^{g} r_{i j \text { out }} \\
C_{\mathrm{B}}\left(n_{i}\right)=\sum_{j=1}^{n} \sum_{k=1}^{n} g_{j k}(i) / g_{j k} \\
C_{\mathrm{C}}\left(n_{i}\right)=1 / \sum_{j=1}^{n} d\left(n_{i}, n_{j}\right)
\end{gathered}
$$

式中: $C_{\mathrm{AD} \text {, in }}\left(n_{i}\right)$ 和 $C_{\mathrm{AD} \text {, our }}\left(n_{i}\right)$ 分别表示节点 $i$ 的内向程 度中心性和外向程度中心性; $r_{i j, \text { in }}$ 和 $r_{i j, \text { out }}$ 分别表示旅 游节点 $i$ 到 $j$ 和 $j$ 到 $i$ 的有向联系; $C_{\mathrm{B}}\left(n_{i}\right)$ 表示节点 $i$ 的 中介中心性; $g_{j k}$ 为节点 $j$ 到 $k$ 的捷径条数, $g_{j k}(i)$ 是旅游 节点 $j$ 和节点 $k$ 之间存在的经过第 3 个点 $i$ 的捷径数 量; $C_{\mathrm{C}}\left(n_{i}\right)$ 表示节点 $i$ 的接近中心性, 包括内向接近中 心性 $C_{\mathrm{C}, \text { in }}$ 和外向接近中心性 $C_{\mathrm{C}, \text { out }} ; d\left(n_{i}, n_{j}\right)$ 是节点 $i$ 与 节点 $j$ 之间的最短路径距离。

(4) 网络中心势。测度人藏旅游流网络的中心 化程度, 当中心势的数值越接近 1 , 表明旅游流网络 的集中趋势越明显。可通过选取程度中心势、中介 中心势和接近中心势 3 个子指标来反映人藏旅游流 网络整体发展的均衡和偏离程度。

$$
\begin{gathered}
C_{\mathrm{AD}}=\frac{\sum_{i=1}^{n}\left(C_{\max }-C_{i}\right)}{(n-1)(n-2)} \\
C_{\mathrm{B}}=\frac{\sum_{i=1}^{n}\left(C_{\mathrm{AB} \max }-C_{\mathrm{AB} i}\right)}{n^{3}-4 n^{2}+5 n-2}
\end{gathered}
$$




$$
C_{\mathrm{C}}=\frac{\sum_{i=1}^{n}\left(C_{\mathrm{C} \max }-C_{\mathrm{C} i}\right)}{(n-1)(n-2)}(2 n-3)
$$

式中: $C_{\mathrm{AD}}$ 为程度中心势, $C_{\max }$ 为节点最大程度中心 性, $C_{i}$ 为节点 $i$ 的程度中心性; $C_{\mathrm{B}}$ 为中介中心势, $C_{\mathrm{ABmax}}$ 为节点中介中心性的最大值, $C_{\mathrm{AB} i}$ 表示节点 $i$ 的中介中心性; $C_{\mathrm{C}}$ 为接近中心势, $C_{\mathrm{C} \text { max }}$ 为节点接近 中心性的最大值, $C_{\mathrm{C} i}$ 是节点 $i$ 的接近中心性。

(5) 结构洞。反映旅游节点在人藏旅游流网络 中的优劣势地位以及网络控制能力, 通过效能大 小、效率性和约束性 3 个指标进行测度。

$$
\begin{gathered}
\mathrm{ES}_{i}=\sum_{j}\left(1-\sum_{i} \sum_{j} p_{i q} m_{j q}\right) \\
E_{i}=\mathrm{ES}_{i} / S_{i} \\
C_{i j}=\left(p_{i j}+\sum_{i} \sum_{j} p_{i q} p_{q j}\right)^{2}
\end{gathered}
$$

式中: $\mathrm{ES}_{i}$ 表示节点 $i$ 效能大小, $j$ 表示与节点 $i$ 相连 的旅游节点, $q$ 是除了 $i$ 和 $j$ 之外的第 3 个节点, $p_{i q} m_{j q}$ 表示节点 $i$ 和旅游节点 $j$ 之间的圥余度; $E_{i}$ 是节点 $i$ 的效率性, $S_{i}$ 代表节点 $i$ 个体网络大小; $C_{i j}$ 为节点 $i$ 受 节点 $j$ 的约束性, $p_{i j}$ 表示节点 $i$ 的全部关系中, 投人 到 $j$ 的关系占比, $p_{i q}$ 表示节点 $i$ 投人到节点 $q$ 的关系 的占比, $p_{q i}$ 代表节点 $q$ 投入到节点 $j$ 的关系的占比。 通过 Ucinet 软件中的 Network/Role \& Positions/ Structual/Profile模块来计算。

（6）核心一边缘结构。反映旅游节点在人藏旅 游流网络中的位置, 判断出网络中的核心和边缘节 点。通过 Ucinet 中的 Network/Core \& periphery/ categorical、continual模块计算。

\section{2 结果分析}

\section{1 入藏旅游流总体上高度集聚, 等级呈现分层分 化现象}

人藏旅游者的旅游线路在空间分布上具有高 度集聚特征,主要集中在拉萨城关区、林芝市巴宜 区、工布江达等地。团队游和自助游的空间分布和 流向存在较大差异。团队游在目的地城市间分布 不均衡, 客流分布和转移范围较小, 覆盖城市仅有 25 个, 到访率占全部节点数量的 $33.78 \%$, 主要集中 在成熟的旅游景区和目的地城市,空间上形成以拉 萨城关区、林芝巴宜区、米林为一级中心, 以日喀则 桑珠孜区、浪卡子、江孜、工布江达、当雄为二级中 心的分布格局, 极化显著。团队游流量规模差异较 大, 最高值达 1013 , 最低值为 1 , 存在不少双向流动 节点, 如城关区与巴宜区、城关区与当雄县、城关区 与浪卡子等(表1)。

自助游覆盖了 60 个节点城市, 到访率高达 $81.08 \%$, 除流向团队游选择的目的地外, 还以各个 区域中心城市为基地, 呈放射状向其他节点转移, 全域化特征显著,形成了以节点城市为中心的扩散 式结构, 分别是以拉萨城关区、当雄、浪卡子为一级 中心, 以林芝巴宜区、日喀则桑珠孜区、墨竹工卡、 工布江达、江孜、贡嘎、米林、堆龙德庆、定日为二级

\begin{tabular}{|c|c|c|c|c|c|c|c|c|}
\hline 类别 & 节点对 & 频次 & 类别 & 节点对 & 频次 & 类别 & 节点对 & 频次 \\
\hline \multirow[t]{14}{*}{ 团队游 } & 墨脱县 $\rightarrow 巴$ 宜区 & 1013 & 团队游 & 定日县 $\rightarrow$ 桑珠孜区 & 49 & 自助游 & 工布江达县 $\rightarrow 巴$ 宜区 & 92 \\
\hline & 城关区 $\rightarrow 巴$ 宜区 & 687 & & 桑珠孜区一城关区 & 46 & & 浪卡子县 $\rightarrow$ 城关区 & 92 \\
\hline & 米林县 $\rightarrow$ 墨脱县 & 449 & & 当雄县 $\rightarrow$ 浪卡子县 & 43 & & 桑珠孜区一定日县 & 87 \\
\hline & 城关区 $\rightarrow$ 工布江达县 & 149 & & 巴宜区 $\rightarrow$ 墨脱县 & 40 & & 米林县 $\rightarrow$ 墨脱县 & 86 \\
\hline & 浪卡子县 $\rightarrow$ 江孜县 & 130 & 自助游 & 当雄县 $\rightarrow$ 城关区 & 195 & & 桑珠孜区 $\rightarrow$ 城关区 & 61 \\
\hline & 江孜县 $\rightarrow$ 桑珠孜区 & 123 & & 城关区 $\rightarrow$ 当雄县 & 179 & & 定日县 $\rightarrow$ 桑珠孜区 & 57 \\
\hline & 浪卡子县 $\rightarrow$ 城关区 & 121 & & 城关区 $\rightarrow$ 浪卡子县 & 141 & & 巴宜区 $\rightarrow$ 工布江达县 & 51 \\
\hline & 巴宜区一米林县 & 98 & & 墨竹工卡县 $\rightarrow$ 工布江达县 & 115 & & 米林县 $\rightarrow 巴$ 宜区 & 51 \\
\hline & 巴宜区一工布江达县 & 90 & & 浪卡子县 $\rightarrow$ 江孜县 & 111 & & 城关区 $\rightarrow$ 桑珠孜区 & 49 \\
\hline & 当雄县 $\rightarrow$ 城关区 & 87 & & 贡嘎县 $\rightarrow$ 城关区 & 106 & & 普兰县 $\rightarrow$ 札达县 & 49 \\
\hline & 墨脱县 $\rightarrow$ 米林县 & 82 & & 巴宜区一米林县 & 102 & & 工布江达县 $\rightarrow$ 城关区 & 47 \\
\hline & 巴宜区一城关区 & 63 & & 江孜县 $\rightarrow$ 桑珠孜区 & 97 & & 桑珠孜区一当雄县 & 46 \\
\hline & 城关区一当雄县 & 57 & & 堆龙德庆县 $\rightarrow$ 城关区 & 96 & & 波密县 $\rightarrow 巴$ 宜区 & 46 \\
\hline & 浪卡子县 $\rightarrow$ 桑珠孜区 & 49 & & 城关区 $\rightarrow$ 墨竹工卡县 & 94 & & 工布江达县 $\rightarrow$ 墨竹工卡县 & 42 \\
\hline
\end{tabular}
中心, 以普兰、札达、波密为三级中心的组织体系。

表 1 入藏团队游和自助游线路出现频次(频次 $\geqslant 40)$

Tab.1 Frequency of group tour and self-guided tour flows to Tibet Autonomous Region 
自助游流量规模差异较小, 流量值在 1 195 之间。 由此可知, 人藏自助游网络相对均衡, 未开发的景 区(点)也是重要选择; 但受交通条件、海拔、知名度 等因素的影响, 仍呈现出东密西疏、南密北疏的空 间结构特征。

\section{2 入藏自助游旅游流“大覆盖”、团队游“小社会” 特征明显}

团队游和自助游网络中涉及不同数量的旅游 节点, 人藏旅游者多为远程客源市场, 旅行时间长、 多采用闭合式游览方式来提高成本一收益比。对 于 $74 \times 74$ 的网络矩阵来说, 旅游流路径理论上有 5402 条, 而在自助游网络中实际观察到的有 3540 条(图 2), 达到 $65.53 \%$, 覆盖面较大, 但紧密程度不 高、节点城镇之间联系不强; 团队游仅有 600 条, 仅 为 $11.11 \%$, 覆盖面较小, 但由于团队游比较集中在 少数城市, 节点联系比自助游紧密。

2.3 入藏旅游流受控于区位交通优势较高的城市,

核心一边缘结构分异显著, 团队游的核心依附 性更强

团队游和自助游 2 个旅游流网络的程度中心势 和接近中心势均较高(表2), 团队游的外向和内向程 度中心势为 $37.33 \%$ 和 $41.67 \%$, 自助游的外向和内 向程度中心势为 $45.65 \%$ 和 $57.71 \%$, 反映出 2 个网络 旅游流的不均衡性, 整体网络受到几个关键核心旅 游节点的控制; 中介中心势较低, 分别为 $17.62 \%$ 、 $16.67 \%$, 反映出多数旅游节点通过某些节点发生旅 游联系。自助游网络中心势的各项指标大多高于 才队游网络, 表明西藏大尺度景观格局下, 团队游 旅游网络中有直接联系的旅游节点较多。

采用核心一边缘分析来判定节点城镇的网络 地位角色, 发现在才队游旅游流网络中, 属于核心
的旅游节点分别是拉萨城关区、林芝巴宜区、当雄、 墨竹工卡、米林、工布江达, 以及山南乃东区、日喀 则桑珠孜区、浪卡子; 在自助游旅游流网络中, 除上 述核心节点外,还包括贡嘎、普兰、尼玛、定日、八宿 和波密; 其他旅游节点在网络中位居边缘或从属地 位。在才队游和自助游旅游流网络中, 核心节点之 间的联结密度分别为 0.75 和 0.80 , 边缘节点联结密 度分别仅为 0.07 和 0.08 , 边缘节点与核心节点之间 的联结密度分别为 0.19 和 0.28 。

2.4 入藏团队游枢纽节点控制性较强, 自助游控制 性节点的数量较少、分布相对均衡

团队游网络中平均每个旅游节点与 5.4 个其他 节点之间存在旅游流集聚或辐射关系,而自助游网 络中则为 12.52 个, 说明人藏旅游者倾向于采用多 目的地型旅行模式, 出游时间长, 与西藏地区旅游 资源 “点多路远、交通不便”的基本特征有关。团队 游和自助游旅游流网络中平均每个旅游节点充当 中介者的次数分别为 5.38 和 1.64(图 3), 团队游网络 中节点对旅游流的控制和依赖作用更强。团队游 和自助游网络中节点的外向和内向接近中心性的 均值分别是 46.95、46.84 和 $52.23 、 52.71$, 自助游网 络中节点之间的联系更为紧密。从中心性指标的 方差来看, 2 个网络中旅游节点之间的分布非常不 平衡(团队游节点的中介中心性的方差为 42.22 , 自 助游节点的内、外向程度中心性的方差分别为 70.95 和 92.32), 表明核心节点在旅游流网络形成过 程中发挥关键作用,部分旅游节点处于被孤立的 地位。

从中心性指标来看, 拉萨城关区、林芝巴宜区、 日喀则桑珠孜区、浪卡子、当雄、定日、米林、工布江 达等程度中心性较高, 占据网络重要位置, 它们拥

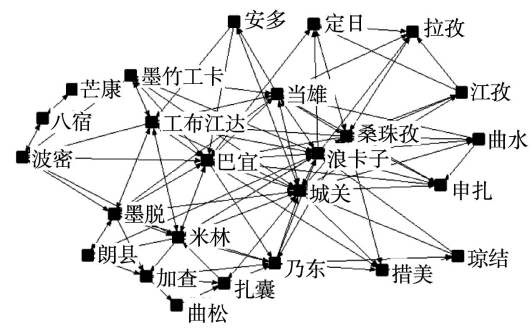

(a) 团队游

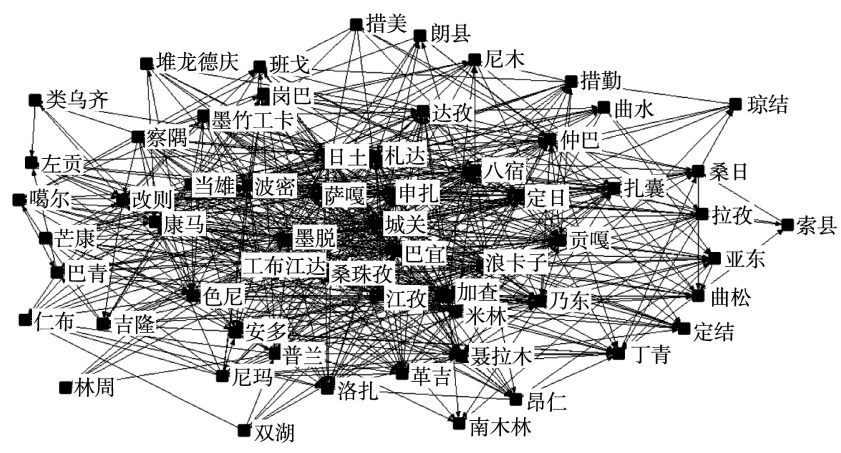

(b) 自助游

图 2 人藏团队游和自助游旅游流网络结构

Fig.2 Network of group tour flows and self-guided tour flows visited Tibet Autonomous Region 
有布达拉宫、罗布林卡、大昭寺、鲁朗林海、雅鲁藏 布大峡谷、珠穆朗玛峰、扎什伦布寺、羊卓雍错、纳 木错、南迦巴瓦峰等高品质旅游资源以及 318 国道

表 2 团队游和自助游旅游流网络中心势

Tab.2 Network centrality index of self-guided tour and group tour flows

$(\%)$

\begin{tabular}{clcc}
\hline \multirow{2}{*}{ 中心势 } & \multirow{2}{*}{ 子指标 } & \multicolumn{2}{c}{ 旅游流网络类型 } \\
\cline { 3 - 4 } & & 团队游 & 自助游 \\
\hline 程度中心势 & 外向程度中心势 & 37.33 & 45.65 \\
& 内向程度中心势 & 41.67 & 57.71 \\
\multirow{2}{*}{ 中介中心势 } & 中介中心势 & 17.62 & 16.67 \\
接近中心势 & 外向接近中心势 & 42.21 & 46.06 \\
& 内向接近中心势 & 34.51 & 59.90 \\
\hline
\end{tabular}

川藏公路、109 国道青藏公路、川藏铁路米林站, 以 及日喀则机场、林芝米林机场等,在旅游流集散中 扮演核心角色,具有旅游流的集聚和扩散功能。其 中, 团队游网络中的拉萨城关区、林芝巴宜区、日喀 则桑珠孜区、波密 4 个节点的中介中心性较高, 对其 他旅游节点起着重要的控制作用; 波密的中介中心 性高达 16.10 , 主要在于波密是连接林芝市巴宜区 与昌都地区、墨脱的必经之路。自助游网络中,拉 萨城关区的中介中心性和接近中心性最高, 桑珠孜 区次之,两者在网络中承担着旅游核心、旅游集散 中心和旅游次核心、旅游次集散中心的角色和功 能; 自助游网络中多数节点的中介中心性和接近中 心性数值相差较小, 表明自助游网络节点联系较均

(a) 团队游 $C_{\mathrm{C}, \text { in }} \quad C_{\mathrm{C}, \text { out }} \quad C_{\mathrm{B}} \quad C_{\mathrm{AD}, \text { in }} \quad \square C_{\mathrm{AD}, \text { out }}$

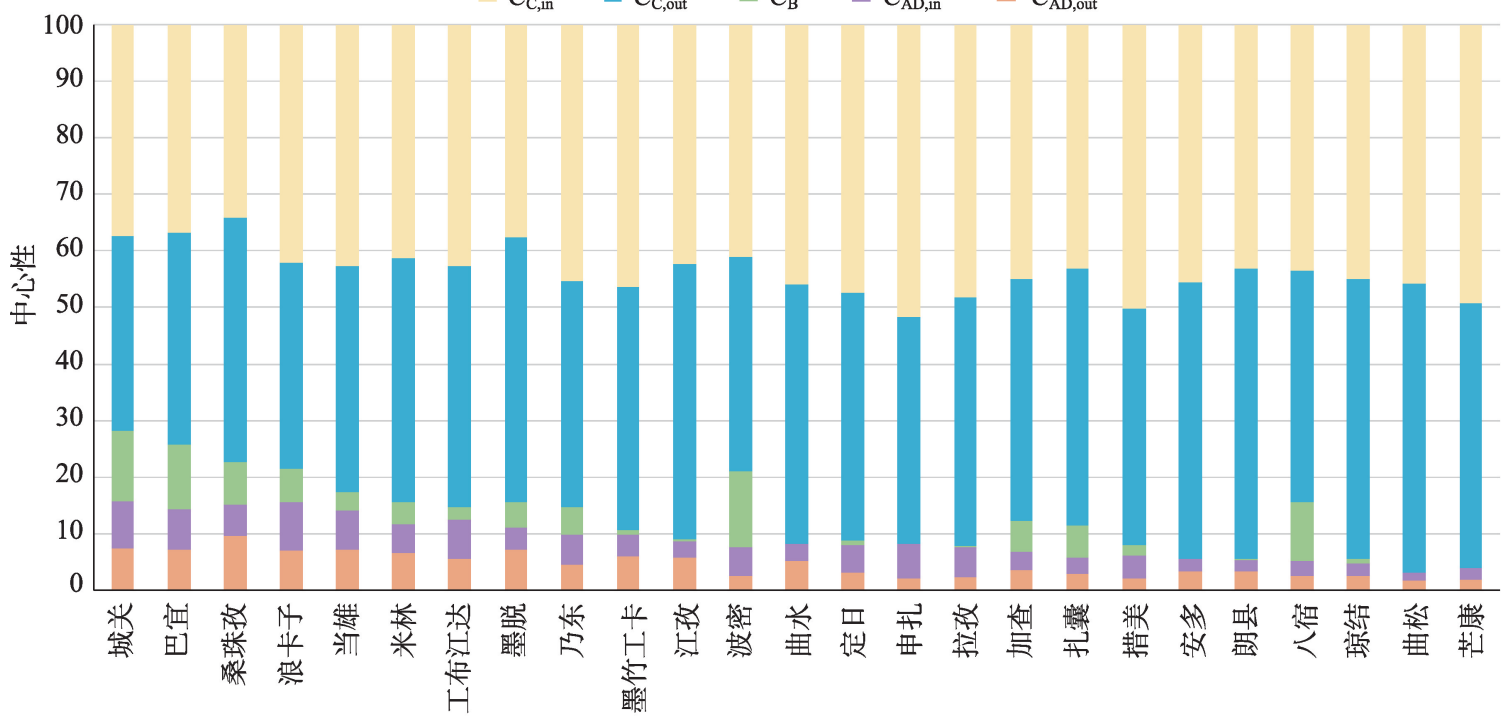

(b) 自助游

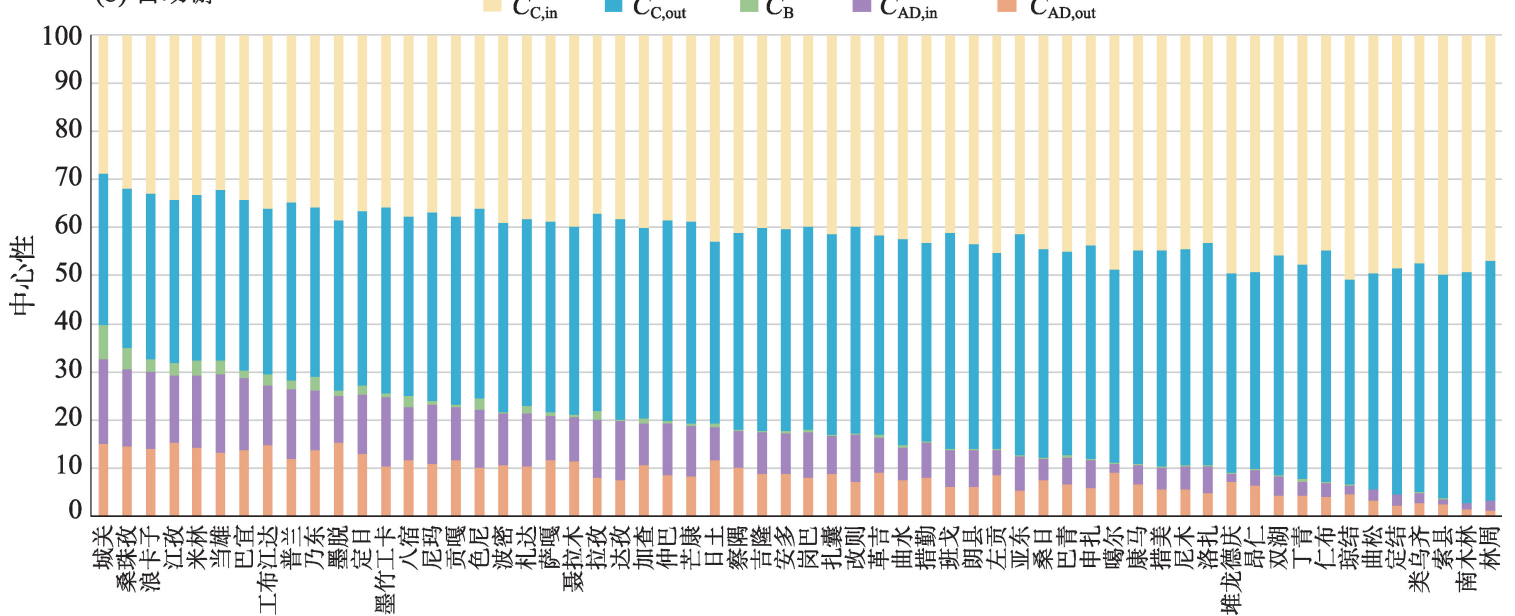

图 3 团队游和自助游旅游流网络中心性结构特征

Fig.3 Structural characteristics of network centrality of group tour flows and self-guided tour flows 
衡, 控制性节点数量较少, 这与自助游出游方式、旅 游偏好有关。

\section{5 入藏旅游流受制于交通节点的程度高于旅游资} 源吸引力, 与内地旅游流形成鲜明差别

采用结构洞模型测算发现(图4), 拉萨城关区、 林芝巴宜区、山南乃东区、日喀则桑珠孜区、浪卡 子、米林和当雄拥有较高的效能、效率性和较低的 约束性, 表明它们处于结构洞位置, 具有较强的关 系优势和区位优势。从图中可知,除拉萨城关区、 林芝巴宜区之外, 其他节点处于重要的交通咽喉位 置, 自身是连接前后向区域的中间节点, 又与其他 节点的交通距离相对较远, 在这段距离上缺乏可替 代的旅游城镇和大型景区, 使交通条件对于人藏旅 游流的控制能力要远远大于旅游资源吸引力, 游客 在进人之后必须首先考虑交通节点的服务设施, 这 与内地和城市地区的旅游流特征完全不同。内地 城市群旅游流网络中, 城镇、景区距离较短, 且配套 设施较齐全, 交通可达性较强 ${ }^{[12,19,27,39]}$, 但具体到人藏 才队游和自助游细分网络上, 团队游网络中具有结
构洞优势的节点数量较少, 内聚力和集聚特征较 强, 接待单次大批量游客首先要考虑住宿、接待、餐 饮等方面的基础需求, 仅在城市中才能够得到满 足; 自助游网络中具有结构洞优势的节点数量则较 多,因为小群体、分散化、机动化的旅行方式对于服 务设施的选择空间相对较大。

\section{3 人藏旅游流组织模式特征与成因}

\section{1 组织模式}

根据人藏旅游流网络结构分析, 可以将西藏旅 游地划分为 3 种类型,包括网络核心节点、网络中转 节点和网络边缘辐射节点。其中网络核心节点属 于综合型城市, 具有人藏交通口岸、区内交通设施 齐全、旅游接待配套完善等综合特点; 网络中转节 点一般处于主干交通线路的通道区间之上, 是上下 层级城镇旅游流动的必经之路, 同时在旅游产品特 色和接待上也有一定能力; 网络边缘辐射节点, 一 般是中转节点目标指向之地, 资源特色明显、品质

(a) 团队游

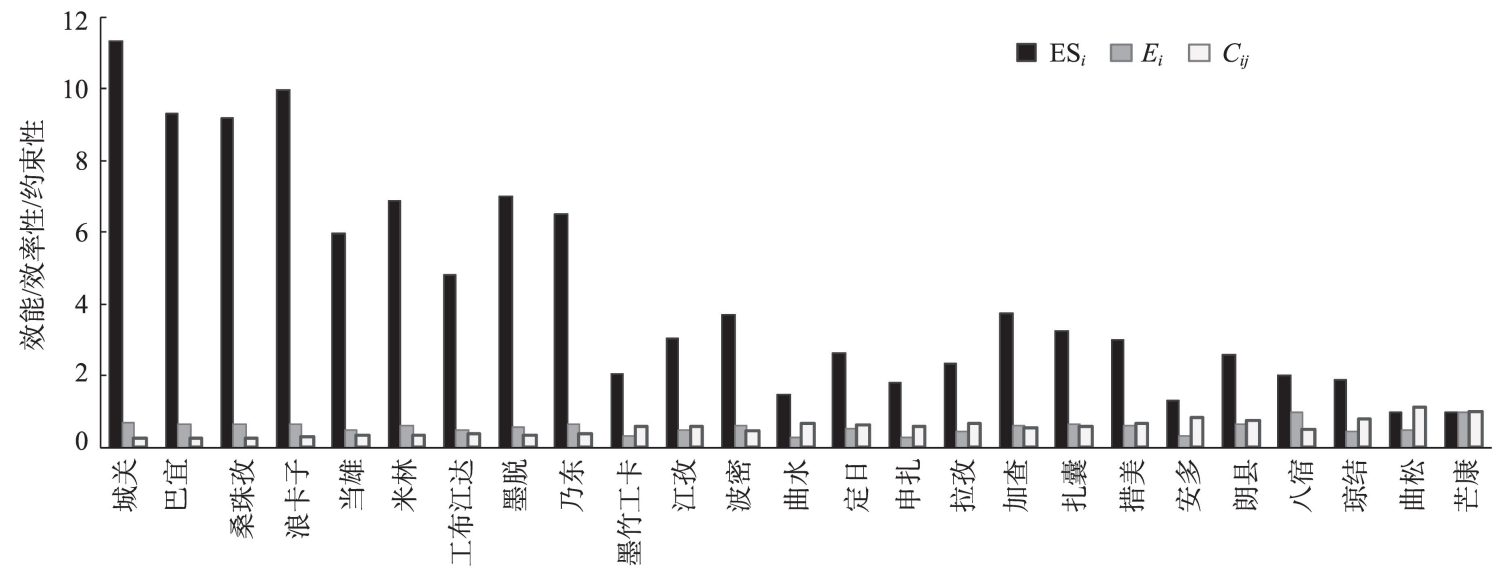

(b) 自助游

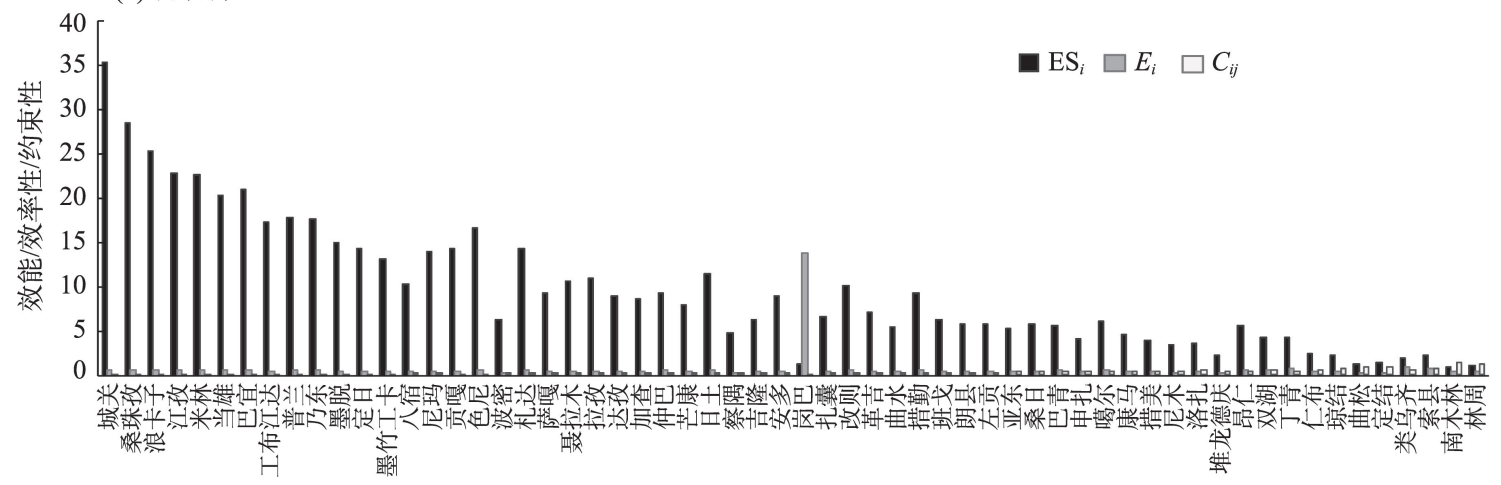

图 4 才队游和自助游旅游流网络结构洞特征

Fig.4 Structural holes of network of group tour flows and self-guided tour flows 
较高,但接待能力一般、交通便捷性也一般,受到的 限制性也较大。由于团队游和自助游在群体、动 机、支出成本等方面的差异, 导致旅游线路出现不 同选择, 从而在旅游流特征呈现上表现为差异性的 旅行模式(图 5)。

团队游和自助游旅行模式分别呈现出 “环游 式”和“周游式”特点, 其中团队游以网络核心节点、 网络中转节点为主(较少涉及网络边缘辐射节点), 在这些节点之间形成一定的流动特点, 出现较多的 在中心区域之间的环游模式。自助游组织模式除 了具有团队游的特征之外, 还表现为从核心节点经 中转节点到边缘辐射节点的规模更大, 在边缘辐射 节点之间的联系也更为广泛和强烈, 可以不通过核 心节点或中转节点直接实现边缘辐射节点连接, 因 为自助游交通方式便捷化, 车辆越野性能也较强, 在外围城镇路况较差的地区可自由穿行。

\section{2 组织模式特征}

3.2.1 人藏旅游流空间流动体现出明显的环(周)游 特征

由于西藏旅游资源的类型特征、空间分布、游 客市场偏好等因素的差异, 人藏旅游流组织模式体 现出典型的区域环游模式或完全环游模式, 即通常 以第一个目的地为起点, 对区内目的地依次进行游 览, 然后按照原路返回第一个目的地, 从而在线路 空间上呈现“圆环” 状; 或者游客从客源地出发, 依 次游览不同旅游地, 不按照原路返回。这 2 种情况 同时存在于人藏团队游和自助游中, 其中团队游以 区域环游模式为主, 即在有限的时间内完成特定区 域的旅游活动, 对于核心依托城市(镇)的依附力较 强; 自助游则多是从西藏某一方向进人, 游览完成
后从另一方向出口结束,网络结构洞数量也较多。 上述组织模式反映了西藏大尺度地域游览的特点, 即特定时间、成本上提高游览数量, 这与中国东部 地区存在的单目的地模式、往返模式、营区基地模 式完全不同 ${ }^{[40]}$ 。东部地区的这些模式在西藏旅游 线路组织中较难执行。

\section{2 .2 人藏旅游流网络紧凑板块的“跨行政区”、面 域组织和发散结构共存}

人藏旅游流分布密度较大的区域集中在以拉 萨、日喀则、林芝为核心, 以及 3 个地市连接沿线的 若干旅游特色城镇, 其他区域主要是通过航空港或 主干交通线连接, 具有绝对的辐射、控制和集散作 用。总体呈现出 2 个特点: 以拉萨为中心向外发展 形成的直飞式的旅游流, 或者以拉萨、日喀则、林芝 为中心向外形成的以自驾车为主体的旅游流。总 体来说, 网络较为紧凑的区域, 体现出跨行政区连 接的紧密特征, 决定了未来西藏区域性旅游产品设 计和线路规划需要考虑跨区域协同发展; 同时由中 心区域和外围区域结合形成的核心一边缘结构, 体 现出典型的内部面域结构和外围发散式结构, 决定 了未来发展中要在中心区域和外围区域选择不同 的线路组织模式,并且在城镇、交通沿线布局旅游 服务设施上要差异化考虑。

\section{2 .3 人藏旅游流受控于交通干线的程度较深, 又 叠加了旅游资源吸引力的复合因素}

旅游交通是联系客源地与目的地的桥梁和纽 带。西藏地广人稀, 交通路网密度和等级不高, 地 市、县城之间通勤距离较长。地市之间一般由国 道、省道连接, 县城之间较好的为省道连接, 多数 仍然是县道甚至是乡道, 中心路网密集、外围稀
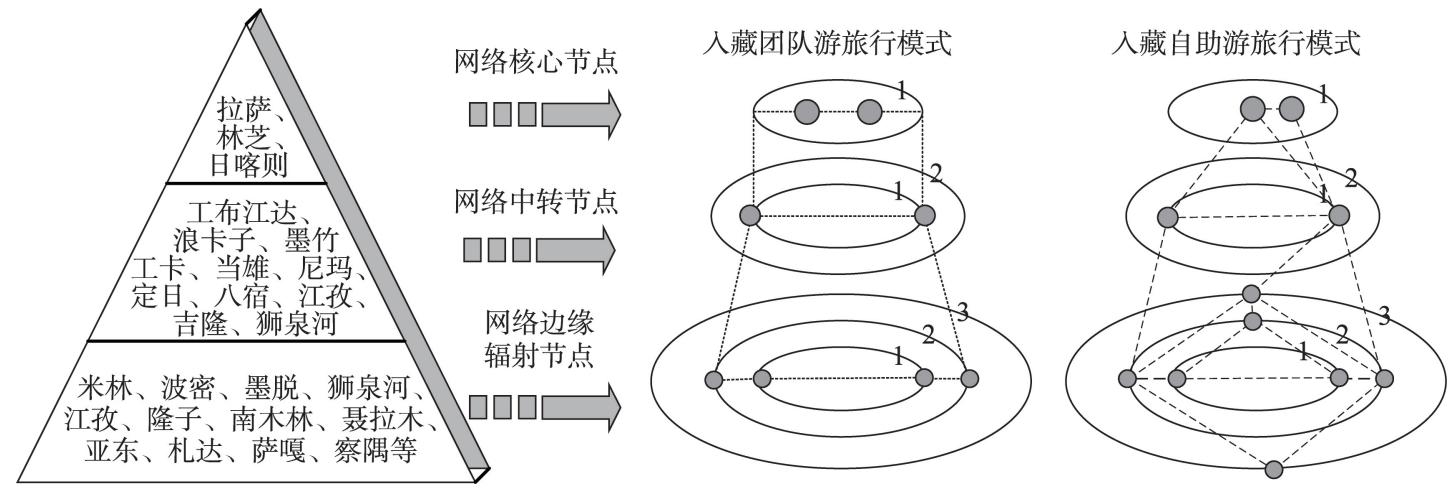

注: 图中 $1 、 2 、 3$ 分别表示核心节点层、中转节点层、边缘辐射节点层。

图 5 人藏旅游目的地层级体系与团队游、自助游组织模式对应关系

Fig.5 Correspondence between destination hierarchy of Tibet and group tour and self-guided tour models 
疏。这种交通路网情况对入藏旅游流活动空间选 择具有较大的影响, 即在保障安全的前提下, 只能 依托路况较好的线路开展游览活动, 且必须提前 规划通行时间和线路, 又要考虑将较好的旅游节 点纳人。因此, 人藏旅游流组织模式同时受到交 通干线布局和旅游资源吸引力的双重影响。

3.2.4 人藏团队游具有明显的 “畏高性”, 自助游体 现出广域、分散式特征

海拔因素是制约旅游者在西藏境内分布与流 动的重要因素之一; 高海拔旅游地对旅游者的身体 素质要求较高。自助游游客通常为身体条件较好 的中青年旅游者, 有一定的探奇、探险的心理, 且在 形成旅游决策之前一般已做好旅游攻略, 能更好地 适应海拔较高、地形更为复杂的普兰县、尼玛县、仲 巴县、双湖县等边缘节点城市; 团队游游客由于旅 行社的组织限制、年龄和身体条件的差异等因素， 高原旅游活动的耐受性较差, 主要选择海拔较低、 景区知名的拉萨城关区、林芝巴宜区、日喀则桑珠 孜区、米林、浪卡子、墨脱等地。因而, 团队游游客 主要集中在西藏平均海拔在 $4000 \mathrm{~m}$ 以下的林芝、拉 萨和日喀则, 自助游全域分布, 大量选择海拔 4000 $\mathrm{m}$ 以上的那曲和阿里等地。

\section{3 组织模式成因}

西藏属于高海拔的大尺度景观区域, 加之地 形、海拔、交通以及旅游资源分布等方面的多种影 响, 使团队游和自助游旅游网络结构和组织模式体 现出不同的发展特征。

首先, 团队游和自助游游客在游客群体、旅游 偏好、出游目的等个体特征方面存在较大差异。团 队游多以中老年群体为主, 活动能力和范围受到一 定限制, 对成熟景区的休闲时间、配套服务要求较 高。自助游多以中青年为主, 户外探险、科研考察 等出游目的较为明显, 并对海拔高度和气候多变的 适应性较强, 配套服务设施不足但旅游资源等级品 质较高的地区仍能成为自助游游客的出游选择。

其次, 旅游交通条件决定了总体层面旅游线路 和旅游流的走向。人藏交通方式包括航空、铁路和 公路 3 种方式。其中: 航空口岸有山南贡嘎机场、林 芝米林机场、昌都邦达机场、阿里昆莎机场以及日 喀则和平机场, 铁路站点有拉萨西站和拉萨站, 公 路有 G219、G318、G109、G317、G214, 这种交通格局 决定了大多数游客出人西藏多选择海拔较低的贡 嘎县、米林县、八宿县和桑珠孜区等机场所在地。
游客人藏之后, 短线团队游客往往以某个配套设施 成熟的节点城市为基地, 沿周边进行基地式游览; 长线团队游客多采用铁路或航空方式前往区内其 他节点城市进行游览, 但仍然采用基地式的旅行模 式。自助游多采用航空或自驾车形式游览多个节 点城市。人藏团队游线路对交通站点和线路依靠 较大, 还要考虑基地周边须有知名度较高的成熟景 区, 以串联形成独立的旅程。自助游主要通过航空 或铁路方式人藏之后, 借助公路游览其他节点城 市, 游线设计要考虑公路可达性的景区。如拉萨城 关区在团队游网络中的中介中心性为 22.29 , 对团 队游的控制能力较强; 但在自助游旅游流网络中的 中介中心性仅为 18.03 , 说明才队游的集散功能要 强于自助游。

第三, 人藏旅游线路设计中选择成熟度和知名 度较高的景区串联为环线, 以保证产品的吸引力和 服务便捷性, 符合大尺度游客力图游览高级别的旅 游景点的规律。团队游线路设计大多包含布达拉 宫、大昭寺、罗布林卡、鲁朗林海、纳木错等。与团 队游相比, 自助游行动自由、人数较少、选择空间 大, 旅游线路除了涉及上述成熟景区外, 还包括资 源价值较高、相对偏远的普兰、尼玛、安多、双湖等 偏远景区甚至是未开发的景观节点。团队游和自 助游依托的集散中心和节点的类型不同, 团队游多 是基地模式,主要依托配套服务能力较强的旅游节 点进行集散; 自助游往往是线性游览模式, 对节点 配套服务的依赖性很强。旅游资源品质高和旅游 配套服务能力较强的旅游节点会成为团队游和自 助游共同的首选之地。但是旅游资源独特性强、品 质高的旅游节点, 虽然相关配套能力不足, 但也会 吸引自驾游客前往。西藏布达拉宫、大昭寺、巴松 措、扎什伦布寺、纳木措、雅鲁藏布江大峡谷等 $5 \mathrm{~A}$ 、 $4 \mathrm{~A}$ 级旅游景区发展较为成熟, 拥有主题酒店、特色 餐馆等较为成熟的旅游配套服务, 吸引了大量团队 游和自助游旅游者。普兰、尼玛、那曲、扎达等旅游 资源品质较高, 旅游配套服务一般, 但对自助游游 客仍有较强的吸引力。

总体来看, 人藏团队游和自助游旅游流结构特 征反映了不同旅游动机下个体和群体空间决策行 为考量因素、目的的差异, 也反映了节点旅游配套 对于游览决策行为的重要影响, 是同一时空下供需 双方进行自适应选择的结果。这种适应性决策过 程影响着人藏旅游流节点的地位和功能, 以及西藏 
旅游交通布局、旅游产品组合、区域旅游协作等多 个方面内容。

\section{4 结论与讨论}

(1) 人藏旅游流在西藏分布具有板块集聚特 征, 多在海拔较低、人藏通道的藏东南地区。人藏 才队游和自助游的空间分布和流向差异较大。团 队游的客流分布和转移范围较小, 仅到访 25 个县 级城市目的地, 拉萨城关区一林芝巴宜区、墨脱 $\rightarrow$ 林芝巴宜区、米林 $\rightarrow$ 墨脱 3 个节点对占团队游总 流量的 50.9\%。自助游客流分布范围广泛, 覆盖了 西藏 60 个县(区), 除流向团队游的热点目的地外, 还以中心城市为基地, 呈放射状向其他目的地 转移。

(2) 人藏团队游和自助游 2 个旅游流网络共性 与差异性共存。共性表现在: 人藏旅游流网络结构 的紧密程度较低, 各节点城市之间的联系不强; 两 个网络的程度中心势和接近中心势较高, 受若干核 心旅游节点的控制明显。差异性体现为: 团队游和 自助游网络中平均每个旅游节点充当中介者的次 数分别为 5.38 和 $1.64,2$ 个网络中节点的外向和内 向接近中心性的均值分别是 $46.95 、 46.84$ 和 52.23 、 52.71 , 表明团队游网络核心节点对旅游流的控制和 依赖作用更强, 而自助游网络中节点间的联系更为 紧密。位居边缘位置的旅游节点应提升自身的配 套服务设施, 加强与核心节点间的合作, 主动承接 核心节点的客流扩散。

(3) 人藏团队游和自助游旅行模式分别呈现出 “环游式” 和“周游式”特征, 网络紧凑板块的 “跨行 政区”现象突出, 受控于交通干线、海拔高度的程度 较深。旅游资源分布与等级、旅游景区的成熟度与 知名度、旅游交通条件、旅游节点的配套服务能力 以及旅游者的个体特征是影响人藏旅游流不同流 动模式和空间组织的主要因素。团队游中某些关 键的旅游节点在自助游中的地位可能被削弱, 自助 游旅游线路中可能会出现新的旅游中心。因此, 要 警惕区域旅游发展的“过道效应”, 优化高原旅游的 “节点放大效应”, 倒逼节点功能提升和业态丰富, 促进旅游产业结构调整。

(4) 本文采用网络游记和旅行社线路报价单搜 索统计的方法开展旅游线路模式研究, 可以获取网 络客群游览节点的点对信息, 进而建构旅游流网络
结构, 得到某一时期特定网络人群的流动行为规 律, 但在样本全面性上存在局限。未来将结合相关 统计数据、手机信号数据等多源数据进行综合分 析, 以期更加完整地刻画人藏旅游流的特征演化 规律。

\section{参考文献(References)}

[1] 裴韬, 舒华, 郭思慧, 等. 地理流的空间模式: 概念与分类 [J]. 地球信息科学学报, 2020, 22(1): 30-40. [Pei Tao, Shu Hua, Guo Sihui, et al. The concept and classification of spatial patterns of geographical flow. Journal of Geo-information Science, 2020, 22(1): 30-40. ]

[2] 汪德根, 陈田, 陆林, 等. 区域旅游流空间结构的高铁效 应及机理: 以中国京沪高铁为例 [J]. 地理学报, 2015, 70 (2): 214-233. [Wang Degen, Chen Tian, Lu Lin, et al. Mechanism and HSR effect of spatial structure of regional tourist flow: Case study of Beijing-Shanghai HSR in China. Acta Geographica Sinica, 2015, 70(2): 214-233. ]

[3] 陈超, 马海涛, 陈楠, 等. 中国农民旅游流网络重心轨迹 的演化 [J]. 地理研究, 2014, 33(7): 1306-1314. [Chen Chao, Ma Haitao, Chen Nan, et al. The evolution of network gravity center for rural residents tourist flow in China. Geographical Research, 2014, 33 (7): 1306-1314. ]

[4] 付琼鸽, 刘大均, 胡静, 等. 湖北省旅游流网络结构的特 征与优化 [J]. 经济地理, 2015, 35(3): 191- 196. [Fu Qiongge, Liu Dajun, Hu Jing, et al. Network structure and optimization research on the Hubei Province tourist flow. Economic Geography, 2015, 35(3): 191-196. ]

[5] 刘丽敏, 钟林生, 虞虎, 等. 青海省自助游与团队游线路 网络空间特征与影响因素 [J]. 经济地理, 2018, 38(1): 187- 195. [Liu Limin, Zhong Linsheng, Yu Hu, et al. Study on the spatial characteristics and influencing factors of independent and group tour routes in Qinghai Province. Economic Geography, 2018, 38(1): 187-195. ]

[6] 唐顺铁, 郭来喜. 旅游流体系研究 [J]. 旅游学刊, 1998, 13(3): 38-41. [Tang Shuntie, Guo Laixi. Research on tourism flow system. Tourism Tribune, 1998, 13(3): 38-41. ]

[7] 张佑印, 马耀峰, 马红丽, 等. 北京人境集聚扩散旅游流 平衡点转移规律研究 [J]. 旅游学刊, 2009, 24(12): 3135. [Zhang Youyin, Ma Yaofeng, Ma Hongli, et al. Study on the dynamic shift of Beijing convergence- diffusion tourism flow equilibrium point. Tourism Tribune, 2009, 24 (12): 31-35. ]

[8] Weaver D B. Peripheries of the periphery: Tourism in Tobago and Barbuda [J]. Annals of Tourism Research, 1998, 25(2): 292-313. 
[9] Rogerson C M, Visser G. International tourist flows and urban tourism in South Africa [J]. Urban Forum, 2006, 17 (2): 199-213

[10] 王永明, 马耀峰, 王美霞. 中国人境游客多城市旅游空 间网络结构 [J]. 地理科学进展, 2012, 31(4): 518-526. [Wang Yongming, Ma Yaofeng, Wang Meixia. Network structure of multicity inbound tourists to China. Progress in Geography, 2012, 31(4): 518-526. ]

[11] 杨兴柱, 顾朝林, 王群. 旅游流驱动力系统分析 [J]. 地理 研究, 2011, 30(1): 23-36. [Yang Xingzhu, Gu Chaolin, Wang Qun. Study on the driving force of tourist flows. Geographical Research, 2011, 30(1): 23-36. ]

[12] 黄泰. 长三角城市群旅游流潜力格局演变及其影响因 素 [J]. 资源科学, 2016, 38(2): 364-376. [Huang Tai. Evolution characteristics and factors affecting tourist flow potential in the Yangtze River Delta Urban Agglomerations. Resources Science, 2016, 38(2): 364-376. ]

[13] 章锦河, 张捷, 李娜, 等. 中国国内旅游流空间场效应分 析 [J]. 地理研究, 2005, 24(2): 293-303. [Zhang Jinhe, Zhang Jie, Li Na, et al. An analysis on spatial field effect of domestic tourist flows in China. Geographical Research, 2005, 24(2): 293-303. ]

[14] Shih H Y. Network characteristics of drive tourism destinations: An application of network analysis in tourism [J]. Tourism Management, 2006, 27(5): 1029-1039.

[15] Hong T, Ma T, Huan T C. Network behavior as driving forces for tourism flows [J]. Journal of Business Research, 2015, 68(1): 146-156.

[16] 杨新菊, 吴晋峰, 唐澜, 等. 旅华外国散客旅游流地理分 布和网络结构研究 [J]. 旅游学刊, 2014, 29(5): 87-96. [Yang Xinju, Wu Jinfeng, Tang Lan, et al. The geographical distribution and network structure of foreign independent tourist flows in China. Tourism Tribune, 2014, 29 (5): 87-96. ]

[17] 邓祖涛, 周玉翠, 梁滨. 武汉城市圈旅游流集聚扩散特 征及路径分析 [J]. 经济地理, 2014, 34(3): 170-175. [Deng Zutao, Zhou Yucui, Liang Bin. Features and routes of agglomeration and diffusion of tourist flows in Wuhan metropolitan area. Economic Geography, 2014, 34(3): 170-175. ]

[18] 张妍妍, 李君轶, 杨敏. 基于旅游数字足迹的西安旅游 流网络结构研究 [J]. 人文地理, 2014, 29(4): 111-118. [Zhang Yanyan, Li Junyi, Yang Min. The tourism flow network structure of Xi'an based on tourism digital footprint. Human Geography, 2014, 29(4): 111-118. ]

[19] 刘军胜, 马耀峰. 基于发生学与系统论的旅游流与目的 地供需耦合成长演化与驱动机制研究: 以西安市为例 [J]. 地理研究, 2017, 36(8): 1583-1600. [Liu Junsheng,
Ma Yaofeng. The evolution and driving mechanism of the supply and demand coupling about tourism flow and destination system based on the genesis and system theory: Taking Xi'an as an example. Geographical Research, 2017, 36(8): 1583-1600. ]

[20] 张春晖, 马耀峰, 白凯. 旅游流与目的地系统耦合研究: 以六大城市人境旅游为例 $[\mathrm{J}]$. 资源科学, 2016, 38(6): 1013-1027. [Zhang Chunhui, Ma Yaofeng, Bai Kai. The system coupling between tourist flow and destination: An empirical analysis of inbound tourism in six major cities. Resources Science, 2016, 38(6): 1013-1027. ]

[21] 王金莹, 吴晋峰, 唐澜, 等. 亚洲人境旅游流地理分布及 网络结构特征分析 [J]. 资源科学, 2013, 35(8): 17011709. [Wang Jinying, Wu Jinfeng, Tang Lan, et al. Distribution of Asian inbound tourist flows and structural characteristics. Resources Science, 2013, 35(8): 1701-1709. ]

[22] 阎友兵, 贺文娟. 国内旅游流流量与流质的时空演化分 析 [J]. 经济地理, 2013, 33(4): 179-185. [Yan Youbing, He Wenjuan. Analysis on the time-space evolution of the domestic tourism flow to China. Economic Geography, 2013, 33(4): 179-185. ]

[23] 刘法建, 张捷, 陈冬冬. 中国人境旅游流网络结构特征 及动因研究 [J]. 地理学报, 2010, 65(8): 1013-1024. [Liu Fajian, Zhang Jie, Chen Dongdong. The characteristics and dynamical factors of Chinese inbound tourist flow network. Acta Geographica Sinica, 2010, 65(8): 1013-1024. ]

[24] 周慧玲, 许春晓. 基于游记行程的湖南旅游流空间网络 结构特征 [J]. 经济地理, 2016, 36(10): 201-206. [Zhou Huiling, Xu Chunxiao. Study on spatial network structure of Hunan tourist flow based on travel arrangement. Economic Geography, 2016, 36(10): 201-206. ]

[25] 践晓峰, 李康康, 陈方. 节假日旅游流时空分异及其形 成机制: 以云南省为例 [J]. 经济地理, 2018, 38(3): 200207. [Ji Xiaofeng, Li Kangkang, Chen Fang. Study on spatial and temporal differentiation of holiday tourism flow and its formation mechanism: A case study of Yunnan Province. Economic Geography, 2018, 38(3): 200207. ]

[26] Hwang Y H, Gretzel U, Fesenmaier D R. Multicity trip patterns: Tourists to the United States [J]. Annals of Tourism Research, 2006, 33(4): 1057-1078.

[27] 市显红, 沙润, 杜长海. 长江三角洲城市人境旅游流区 域内流动份额分析 [J]. 人文地理, 2007, 22(2): 32-38. [Bian Xianhong, Sha Run, Du Changhai. Analysis on regional floating share of inbound tour flow in the Yangtze River Delta. Human Geography, 2007, 22(2): 32-38. ]

[28] 间闪闪, 靳诚. 市域内部旅游流空间扩散动力机制: 以 
洛阳市为例 [J]. 人文地理, 2019, 34(5): 149-158. [Yan Shanshan, Jin Cheng. The dynamic mechanism of the city domestic tourist flow space: A case study of Luoyang. Human Geography, 2019, 34(5): 149-158. ]

[29] 杨兴柱, 顾朝林, 王群, 等. 南京市内部旅游客流空间测 度与模拟 [J]. 地理科学, 2011, 31(7): 802-809. [Yang Xingzhu, Gu Chaolin, Wang Qun, et al. Spatial measure and simulation of urban tourism flow in Nanjing City, China. Scientia Geographica Sinica, 2011, 31(7): 802809. ]

[30] 查晓莉, 徐雨晨, 陆林, 等. 上海迪士尼国内旅游流地理 分布与流动特征 [J]. 旅游学刊, 2019, 34(6): 58-73. [Zha Xiaoli, Xu Yuchen, Lu Lin, et al. Geographical distribution and flows of Chinese tourists to Shanghai Disneyland. Tourism Tribune, 2019, 34(6): 58-73. ]

[31] 刘宏盈. 广东人境旅游流西向扩散距离衰减规律研 究 [J]. 经济地理, 2012, 32(11): 162-165, 170. [Liu Hongying. The distance attenuation rules of Guangdong inbound tourism flow's western towards diffuse. Economic Geography, 2012, 32(11): 162-165, 170. ]

[32] 崔庆明, 徐红罡, 杨杨. 世俗的朝圣: 西藏旅游体验研究 [J]. 旅游学刊, 2014, 29(2): 110-117. [Cui Qingming, Xu Honggang, Yang Yang. Secular pilgrimage: Tourist experience in Tibet. Tourism Tribune, 2014, 29(2): 110-117. ]

[33] 甘露, 卢天玲, 王晓辉. 国内人藏游客对西藏旅游形象 感知的实证研究 [J]. 旅游科学, 2013, 27(2): 73-82. [Gan Lu, Lu Tianling, Wang Xiaohui. An empirical study of the domestic tourists' perception on Tibet's tourism image. Tourism Science, 2013, 27(2): 73-82. ]

[34] 张朝枝, 张金金. 流动性的旅游体验模型建构: 基于骑行 人藏者的研究 [J]. 地理研究, 2017, 36(12): 2332-2342. [Zhang Chaozhi, Zhang Xin. Constructing a mobile travel experience model: Empirical study of cyclists travelling to Tibet. Geographical Research, 2017, 36(12): 23322342. ]
[35] 钟林生, 王婧, 唐承财. 西藏温泉旅游资源开发潜力评 价与开发策略 [J]. 资源科学, 2009, 31(11): 1848-1855. [Zhong Linsheng, Wang Jing, Tang Chengcai. Assessing development potential of hot spring tourism resources in Tibet. Resources Science, 2009, 31(11): 1848-1855. ]

[36] 杨建鹏, 丁玲辉. 西藏乡村旅游与民族节庆和藏族传统 体育文化融合发展研究 $[\mathrm{J}]$. 西南民族大学学报(人文社 科版), 2016, 37(1): 46-50. [Yang Jianpeng, Ding Linghui. Rural tourism and ethnic festivals in Tibet research on the integration and development of traditional Tibetan sports culture. Journal of Southwest for Nationalities (Humanities and Social Science), 2016, 37(1): 46-50. ]

[37] 徐宁, 图登克珠. “一带一路” 背景下西藏边境旅游发展 的战略选择 [J]. 西藏大学学报(社会科学版), 2016(2): 147- 152. [Xu Ning, Tubden Kyedrub. On strategic choice of Tibet's border tourism development. Journal of Tibet University (Social Sciences), 2016(2): 147-152. ]

[38] 朱冬芳, 陆林, 虞虎. 基于旅游经济网络视角的长江三 角洲都市圈旅游地角色 [J]. 经济地理, 2012, 32(4): 149-154, 135. [Zhu Dongfang, Lu Lin, Yu Hu. Analysis on the roles of tourism destinations in the Yangtze River Delta metropolitan area: Based on the perspective of tourism economy. Economic Geography, 2012, 32(4): 149154, 135. ]

[39] 刘大均. 城市群旅游流空间格局及演化研究: 以长江中 游城市群为例 [D]. 武汉: 华中师范大学, 2016. [Liu Dajun. Study on the spatial structure and evolution of urban agglomeration tourist flow: A case study of urban agglomeration in the middle reaches of the Yangtze River. Wuhan, China: Central China Normal University, 2016. ]

[40] 陆林, 汤云云. 珠江三角洲都市圈国内旅游者空间行为 模式研究 [J]. 地理科学, 2014, 34(1): 10-18. [Lu Lin, Tang Yunyun. Spatial behavior patterns of domestic tourists of the Zhujiang River Delta metropolitan area. Scientia Geographica Sinica, 2014, 34(1): 10-18. ] 


\title{
Network structure characteristics and organizational models of tourist flow to Tibet: Comparative analysis based on group and self-guided tours
}

\author{
ZHU Dongfang ${ }^{1,2}$, YU Hu', LIU Qingqing ${ }^{3 *}$, LIU Limin ${ }^{4}$ \\ (1. Institute of Geographic Sciences and Natural Resources Research, Key Laboratory of Regional Sustainable \\ Development Analysis and Simulation, CAS, Beijing 100101, China; \\ 2. College of Resources and Environment, University of Chinese Academy of Sciences, Beijing 100049, China; \\ 3. College of Tourism and Exhibition, Henan University of Economics and Law, Zhengzhou 450000, China; \\ 4. School of Management, China Women's University, Beijing 100101, China)
}

\begin{abstract}
As a large-scale landscape region, Tibet has ubiquitous and decentralized tourism resources, unique landscape, and layout of transportation routes. The various natural conditions such as terrain, altitude, and climate make tourist flows in Tibet completely different from other regions, especially for group and self-guided tours. This study collected data on group tour and self-guided tour from popular tourism websites, and combined social network analysis to explore the network structure characteristics and organizational models of tourist flows to Tibet, providing a theoretical reference for the optimal organization of Tibet tourism destinations. The study found that the tourist flow into Tibet is characterized by overall agglomeration and hierarchical differentiations. The nodes are not closely connected and the core-periphery structure is obvious. Group tour is strongly dependent on hub nodes and traffic, and self-guided tour covers a large area. Group tour and self-guided tour modes present "destination area loop" and dispersion features, respectively, and the phenomenon of crossing administrative regions in the compact network segment is prominent and largely controlled by the main traffic routes. The difference between tourist flows of group tour and self-guided tour reflects the joint influence of terrain, altitude, transportation, tourism resource distribution, and consumption ability. It is the result of spatial decision-making of individuals and groups under different tourism motives and the comprehensive effect of multiple factors, and has influenced the development of tourism transportation layout, tourism product combination, and regional tourism cooperation in Tibet. The research results provide a reference for understanding the flow and movement patterns of tourists entering Tibet for group tour and self-guided tour, and it can provide a theoretical guidance for the optimization of tourist route design and collaborative planning of tourist destinations in Tibet.
\end{abstract}

Keywords: network of tourist flow to Tibet; organizational models; large-scale landscape region; Tibet 